УДК $572.08+616-001.1 / 5$

https://doi.org/10.24852/2587-6112.2021.2.325.337

\title{
ПАЛЕОАНТРОПОЛОГИЧЕСКОЕ И ПАЛЕОПАТОЛОГИЧЕСКОЕ ИССЛЕДОВАНИЕ НАСЕЛЕНИЯ НИЖНЕГО ПРИКАМЬЯ РУБЕЖА ЭПОХ ПО МАТЕРИАЛАМ ИЖЕВСКОГО МОГИЛЬНИКА ${ }^{1}$
}

\author{
(С) 2021 г. Е.В. Волкова, И.Р. Газимзянов, К.В. Кирягин, В.А. Калянов
}

Статья посвящена изучению краниологических материалов Ижевского могильника. В распоряжении исследователей была серия из 19 мужских и 26 женских черепов. Мужские черепа суммарно характеризуются как долихо-мезокранные с низкой высотой свода и умеренным развитием мышечного рельефа в области затылка и лба. Лицевой скелет - среднеширокий и средневысокий, по пропорциям - мезенный. В общей вертикальной проекции лицо мезогнатно, а в альвеолярной - прогнатно. В целом мужские черепа Ижевского могильника относятся к европеоидным формам, но с нерезко выраженными признаками, что может указывать на присутствие в серии монголоидного компонента. Женские черепа, с учетом полового диморфизма, мало чем отличались от мужских за исключением меньшего угла выступания носа, что может указывать на более выраженный монголоидный компонент. Краниологическая серия Ижевского могильника, независимо от половой принадлежности, суммарно характеризуется как европеоидная, но с включением некоторой доли монголоидной примеси, которая больше всего выявляется в женской ее части. Серия из Ижевского могильника, по своим морфологическим особенностям - удлиненная форма черепа, узкое и средневысокое лицо в сочетание с умеренной горизонтальной профилировкой и средним выступанием носовых костей - входит в круг поволжско-приуральских серий эпохи рубежа эр, которые представляют в антропологическом плане население пьяноборской, мазунинской, караабызской, азелинской, гляденовской и бахмутинской культур. Вероятно, формирование физического облика данного населения проходило на общей морфологической основе (европеоидной, в целом), что, впрочем, не исключает генетического влияния отдельных «южных» европеоидных и более монголоидных «восточных» групп. Палеопатологический анализ останков Ижевского могильника позволил зафиксировать и охарактеризованы травмы, которые были обнаружены на четырех черепах $(9,5 \%)$ и восьми скелетах $(11 \%)$. Остеомаляция и встречаемость маркёров физиологического стресса (в половине случаев) свидетельствуют о неблагоприятных условиях жизни популяции, захороненной в Ижевском могильнике.

Ключевые слова: физическая антропология, краниология, травма, маркёры физиологического стресса, возрастные изменения скелета, патология, Ижевский могильник, формирование физического облика населения, мазунинская археологическая культура, Нижнее Прикамье.

\section{PALEOANTHROPOLOGICAL AND PALEOPATHOLOGICAL STUDY OF THE LOWER KAMA BASIN POPULATION OF TURN OF THE ERAS ACCORDING TO THE MATERIALS OF IZHEVSK BURIAL GROUND ${ }^{2}$}

\author{
E.V. Volkova, I.R. Gazimzyanov, K.V. Kiryagin, V.A. Kalyanov
}

The article is dedicated to a study of craniological materials from Izhevsk burial ground. The researchers had at their disposal a series of 19 male and 26 female skulls. The male skulls are generally characterized as dolicho-mezokranial with a low arch height and moderate development of muscle relief in the neck and forehead. The facial skeleton is medium-wide, medium-high, and medium in terms of proportion. In the general vertical projection, the face is mesognathic, and in the alveolar projection - prognathic. Overall, the male skulls from Izhevsk burial ground belong to caucasoid forms, but with non-moderate features, which may indicate the presence of a mongoloid component. The female skulls, with due account of sexual dimorphism, were not much different from the male skulls, with the exception of a smaller protruding angle of the nose, which can indicate a more pronounced mongoloid component. The craniological series of the Izhevsk burial ground, regardless of gender, is summarized as Caucasoid, but with the inclusion of a certain portion of Mongoloid im-

Работа выполнена в рамках государственного задания ИА (2019-2021) по теме 2.2 «Культурные и хронологические группы оседлого населения лесостепной зоны Поволжья и Прикамья в первой половине середине I тысячелетия н.э.»

The work was carried out within the framework of the state task of the IA (2019-2021) on the topic 2.2 " Cultural and chronological groups of the sedentary population of the forest-steppe zone of the Volga and Kama regions in the first half - middle of the first millennium AD.» 
purity, which is most pronounced in its female portion. The series from Izhevsk burial ground, according to its morphological features - an elongated skull, narrow and medium-high face combined with moderate horizontal profiling and medium protrusion of the nasal bones is included in the Volga-Ural series of the turn of the epochs, which anthropologically represent the population of the Pyany Bor, Mazunino, Kara-abyz, Azelino, Gladenovo and Bakhmutino cultures. Probably, the formation of the physical appearance of this population took place on a common morphological basis (Caucasoid as a whole), which, however, does not exclude the genetic influence of individual "southern" Caucasoid and more Mongoloid "eastern" groups. A paleo-pathological analysis of the remains of the finds from Izhevsk burial ground has allowed to trace and characterize trauma on 4 skulls $(9.5 \%)$ and 8 skeletons (11\%). The osteomalacia and occurrence rate of physiological stress markers (in half of the cases) indicate severe living conditions of the population buried at Izhevsk burial ground.

Keywords: physical anthropology, craniology, trauma, the physiologic stress markers, age-related skeletal changes, pathology, Izhevsk burial ground, formation of the physical appearance of the population, Mazunino archaeological culture, Lower Kama Region.

Ижевский могильник был обнаружен весной 1957 года случайно местными жителями. Несколько вещей были найдены детьми на ул. Безымянной г. Ижевска. Осенью того же года силами студентов Удмуртского государственного педагогического института под руководством В.Ф. Генинга была вскрыта площадь 225 кв. м, где было обнаружено 38 погребений. Их культурная принадлежность была определена В.Ф. Генингом как мазунинская, могильник датирован IV-V вв. н. э. Для

последующего изучения памятника в 1975 году раскопки могильника были продолжены экспедициями Республиканского краеведческого музея и Удмуртского государственного университета под руководством Т.И. Останиной. На вскрытой площади в 1301 кв. м было обнаружено 173 погребения. Могильник расположен на невысоком плоском мысу левого берега реки Иж, ныне Ижевского пруда (ул. Безымянная). С южной стороны площадка могильника была окаймлена оврагом, по

Некоторые краниометрические параметры серии мужских черепов Ижевского могильника Таблииа 1. Craniometric parameters of the series of male skulls from Izhevsk burial ground

Table 1.

\begin{tabular}{|c|c|c|c|}
\hline Признак & $\mathrm{N}$ & $\mathrm{X}$ & $\bar{S}$ \\
\hline 1. Продольный диаметр & 16 & 187.5 & 7.11 \\
\hline 8. Поперечный диаметр & 17 & 141.6 & 4.90 \\
\hline 17. Высотный диаметр & 13 & 133.5 & 6.33 \\
\hline 9. Наименьшая ширина лба & 24 & 96.2 & 3.97 \\
\hline 45. Скуловой диаметр & 19 & 135.5 & 3.78 \\
\hline 48. Верхняя высота лица & 24 & 72.3 & 4.12 \\
\hline 55. Высота носа & 24 & 50.9 & 3.79 \\
\hline 54. Ширина носа & 23 & 25.1 & 1.65 \\
\hline 51. Ширина орбиты от mf. & 24 & 41.0 & 1.68 \\
\hline 52. Высота орбиты & 24 & 32.9 & 3.19 \\
\hline 77. Назомалярный угол & 20 & 140.6 & 5.53 \\
\hline Zm. Зигомакиллярный угол & 19 & 129.8 & 3.25 \\
\hline SS. Симотическая высота & 17 & 4.2 & 1.07 \\
\hline DS. Дакриальная высота & 14 & 12.3 & 0.99 \\
\hline Глубина клыковой ямки (мм) & 23 & 4.4 & 2.01 \\
\hline 32. Угол лба & 18 & 85.1 & 5.58 \\
\hline 72. Общий лицевой угол & 17 & 84.4 & 4.44 \\
\hline 74. Альвеолярный угол & 16 & 80.7 & 6.49 \\
\hline 75(1). Угол носа & 13 & 27.2 & 4.60 \\
\hline $8: 1$. Черепной указатель & 14 & 75.4 & 3.83 \\
\hline $17: 1$. Высотно-продольный указатель & 13 & 71.2 & 3.14 \\
\hline $17: 8$. Высотно-поперечный указатель & 11 & 85.3 & 28.22 \\
\hline $9: 8$. Лобный указатель & 14 & 68.2 & 1.89 \\
\hline $48: 45$. Верхне-лицевой указатель & 18 & 53.0 & 3.50 \\
\hline $54: 55$. Носовой указатель & 23 & 49.2 & 3.80 \\
\hline $52: 51$. Орбитный указатель & 24 & 78.5 & 9.57 \\
\hline SS SC. Симотический указатель & 17 & 47.2 & 9.54 \\
\hline DS DC. Дакриальный указатель & 14 & 56.8 & 6.89 \\
\hline
\end{tabular}


дну которого протекал родник, впадающий в пруд, а с севера - поймой реки Подборенки (рис. 1) (Генинг, 1967; Останина, 1984).

Антропологические материалы Ижевского могильника ранее исследовались Фаттаховым P.М. (1981). Краниологическая серия Ижевского могильника представлена 50 черепами, 19 из которых отнесены к мужским, 26 - к женским, 5 черепов принадлежат индивидам детской возрастной группы. На данный момент антропологические материалы могильника находятся на хранении в Институте археологии им. А.Х. Халикова АН РТ (г. Казань, Республика Татарстан).

Было проведено краниологическое исследование серии черепов в соответствии с принятыми в отечественной антропологии методиками (Алексеев, Дебец, 1964).

Мужские черепа суммарно характеризуются как долихо-мезокранные с низкой высотой свода и умеренным развитием мышечного рельефа в области затылка и лба (табл. 1). Таблий 2.

Table 2.

Некоторые краниометрические параметры серии женских черепов Ижевского могильника

Craniometric parameters of the series of female skulls from Izhevsk burial ground

\begin{tabular}{|c|c|c|c|}
\hline Признак & $\mathrm{N}$ & $\mathrm{X}$ & $\mathrm{S}$ \\
\hline 1. Продольный диаметр & 13 & 179.6 & 5.11 \\
\hline 8. Поперечный диаметр & 14 & 132.7 & 5.90 \\
\hline 17. Высотный диаметр & 11 & 129.7 & 4.96 \\
\hline 9. Наименьшая ширина лба & 16 & 93.8 & 3.28 \\
\hline 45. Скуловой диаметр & 13 & 124.6 & 4.29 \\
\hline 48. Верхняя высота лица & 18 & 66.2 & 3.10 \\
\hline 55. Высота носа & 18 & 46.3 & 2.68 \\
\hline 54. Ширина носа & 18 & 25.8 & 2.05 \\
\hline 51. Ширина орбиты от mf. & 17 & 40.4 & 1.33 \\
\hline 52. Высота орбиты & 17 & 32.2 & 2.02 \\
\hline 77. Назомалярный угол & 14 & 142.1 & 5.15 \\
\hline Zm. Зигомакиллярный угол & 12 & 128.8 & 4.35 \\
\hline SS. Симотическая высота & 15 & 2.9 & 0.81 \\
\hline DS. Дакриальная высота & 11 & 11.0 & 1.83 \\
\hline Глубина клыковой ямки (мм) & 16 & 4.1 & 1.84 \\
\hline 32. Угол лба & 9 & 85.0 & 2.69 \\
\hline 72. Общий лицевой угол & 9 & 83.6 & 2.74 \\
\hline 74. Альвеолярный угол & 9 & 74.9 & 5.58 \\
\hline 75(1). УГол носа & 9 & 20.4 & 5.57 \\
\hline $8: 1$. Черепной указатель & 13 & 74.2 & 4.30 \\
\hline 17 : 1. Высотно-продольный указатель & 11 & 72.9 & 2.42 \\
\hline 17 : 8. Высотно-поперечный указатель & 10 & 97.0 & 3.91 \\
\hline 9 : 8. Лобный указатель & 13 & 70.8 & 2.42 \\
\hline $48: 45$. Верхне-лицевой указатель & 13 & 52.7 & 2.83 \\
\hline $54: 55$. Носовой указатель & 18 & 55.8 & 5.23 \\
\hline $52: 51$. Орбитный указатель & 17 & 79.9 & 6.09 \\
\hline SS SC. Симотический указатель & 15 & 37.2 & 8.04 \\
\hline DS DC. Дакриальный указатель & 10 & 50.3 & 8.66 \\
\hline
\end{tabular}

Лицевой скелет среднеширокий и средневысокий, по пропорциям - мезенный. В общей вертикальной проекции лицо мезогнатно, а в альвеолярной - прогнатно. В горизонтальной плоскости лица отмечается умеренная его профилировка, как на уровне орбит, так и на уровне скул. Переносье средневысокое и хорошо профилировано, угол выступания носа средний. Глубина клыковой ямки большая. В строении нижнего края носового отверстия преобладают заостренные формы. В целом мужские черепа Ижевского могильника относятся к европеоидным формам, но с нерезко выраженными признаками, что может указывать на присутствие в серии монголоидного компонента.

Женские черепа морфологически, с учетом полового диморфизма, мало чем отличались от мужских (табл. 2). Единственное, но существенное, что их различает, так это меньший угол выступания носа в женской группе. Его значение (20,4 градуса) не характерно для европеоидных групп, что может указывать на более выраженный монголоидный компонент в ее составе.

Таким образом, краниологическая серия Ижевского могильника, независимо от половой принадлежности, суммарно характеризу- 
Результаты внутригруппового анализа главных компонент. Ижевский могильник. Мужчины Results of intragroup analysis of the main components. Izhevsk burial mound. Men

Таблица 3.

Table 3.

\begin{tabular}{|c|c|c|c|}
\hline \multirow[t]{2}{*}{ Признаки } & \multicolumn{3}{|c|}{ Главные компоненты } \\
\hline & $\mathrm{I}$ & II & III \\
\hline 1. Продольный диаметр & -0.100 & 0.430 & $0.596 *$ \\
\hline 8. Поперечный диаметр & -0.395 & $0.517 *$ & 0.208 \\
\hline 17. Высотный диаметр & 0.280 & -0.150 & $0.592 *$ \\
\hline 9. Наим. ширина лба & -0.195 & $0.862 *$ & 0.171 \\
\hline 45. Скуловой диаметр & 0.009 & 0.405 & $-0.685^{*}$ \\
\hline 48. Верхняя высота лица & $0.764 *$ & 0.317 & 0.275 \\
\hline 55. Высота носа & $0.867 *$ & 0.238 & 0.066 \\
\hline 54. Ширина носа & -0.081 & $0.633 *$ & -0.339 \\
\hline 51. Ширина орбиты (от mf) & 0.451 & $0.667 *$ & -0.194 \\
\hline 52. Высота орбиты & 0.296 & 0.152 & 0.383 \\
\hline 32. Угол профиля лба & -0.333 & $0.617 *$ & -0.033 \\
\hline 77. Назомалярный угол & $-0.503 *$ & -0.148 & -0.204 \\
\hline Zm’. Зигомаксиллярный угол & $-0.697 *$ & 0.271 & 0.168 \\
\hline SS:SC. Симотический указатель & $0.538 *$ & 0.033 & -0.004 \\
\hline 75(1). Угол носа & 0.461 & 0.027 & $-0.650 *$ \\
\hline Общая дисперсия (\%) & 21.8 & 19.2 & 14.1 \\
\hline
\end{tabular}

*- выделены значения, указывающие на сильную коррелятивную связь

ется как европеоидная, но с включением некоторой доли монголоидной примеси, которая больше всего выявляется в женской ее части. Индивидуально-типологический анализ ижевских черепов и анализ эмпирических значений квадратического уклонения в серии по отношению их к стандартным показывает, что по многим признакам серия в антропологическом плане неоднородна.

Представление о характере внутри-групповых связей ижевской серии дает метод главных компонент. Для анализа привлечено 14 мужских черепов хорошей сохранности (в ряде случаев недостающие значения некоторых признаков заменялись средними групповыми). Набор признаков, имеющих повышенную таксономическую значимость $-1,8$, $17,9,45,48,55,54,51,52,32,77$, zm', ss:sc, 75(1). Наиболее полную информацию несут первые три главных компонента, отражающие в общей совокупности более 55\% от всей внутригрупповой изменчивости (табл. 3).

Первая главная компонента $(21,8 \%$ от всей дисперсии) выявляет следующую внутригрупповую закономерность: с увеличением высоты лица увеличивается высота носа и высота переносья. В то же время уменьшаются значения горизонтальной профилировки на обоих уровнях. Вероятно, данная взаимосвязь признаков статистически подтверждает наличие в мужской серии черепов европеоидного типа со следующими морфологическими характеристиками: более высокому лицу соответствует более резкая его профилировка на уровне орбит и скул, а также более высокое переносье и, наоборот, монголоидные черепа с более низким, уплощенным лицом и низким переносьем.

Во второй главной компоненте (19,26\%) основные нагрузки падают на ширину лба, ширину орбит, ширину носа, угол профиля лба и поперечный диаметр. Эти признаки образуют следующую взаимосвязь: с увеличением ширины лба соответственно увеличивается ширина орбит и носа, а также ширина мозговой коробки и угол профиля лба. Возможно, данная компонента выделяет в анализируемой совокупности черепа смешанного антропологического типа.

Третья компонента, отражающая более $14 \%$ от всей внутригрупповой дисперсии, более наглядно выделяет черепа смешанного физического облика. Для одних характерна более длинная и высокая черепная коробка с узким лицом, но с небольшим углом носа, а для других - более широкая и низкая мозговая капсула с широким лицом, но с более выступающим носом.

Графическое расположение мужских черепов в пространстве первых двух главных компонент (более $40 \%$ от всей изменчивости) показало в целом их дисперсное распределение на корреляционном поле (рис. 1). Интерпретация такой морфологической ситуации, когда черепа Ижевского могильника не образуют каких-либо закономерных группировок, довольно затруднительна. Вероятнее всего, они представляют переходные или промежуточные типы как результат метисации между исходными компонентами, которые в свою 
Ижевский могильник. Мужские черепа в пространстве двух первых главных компонентов.

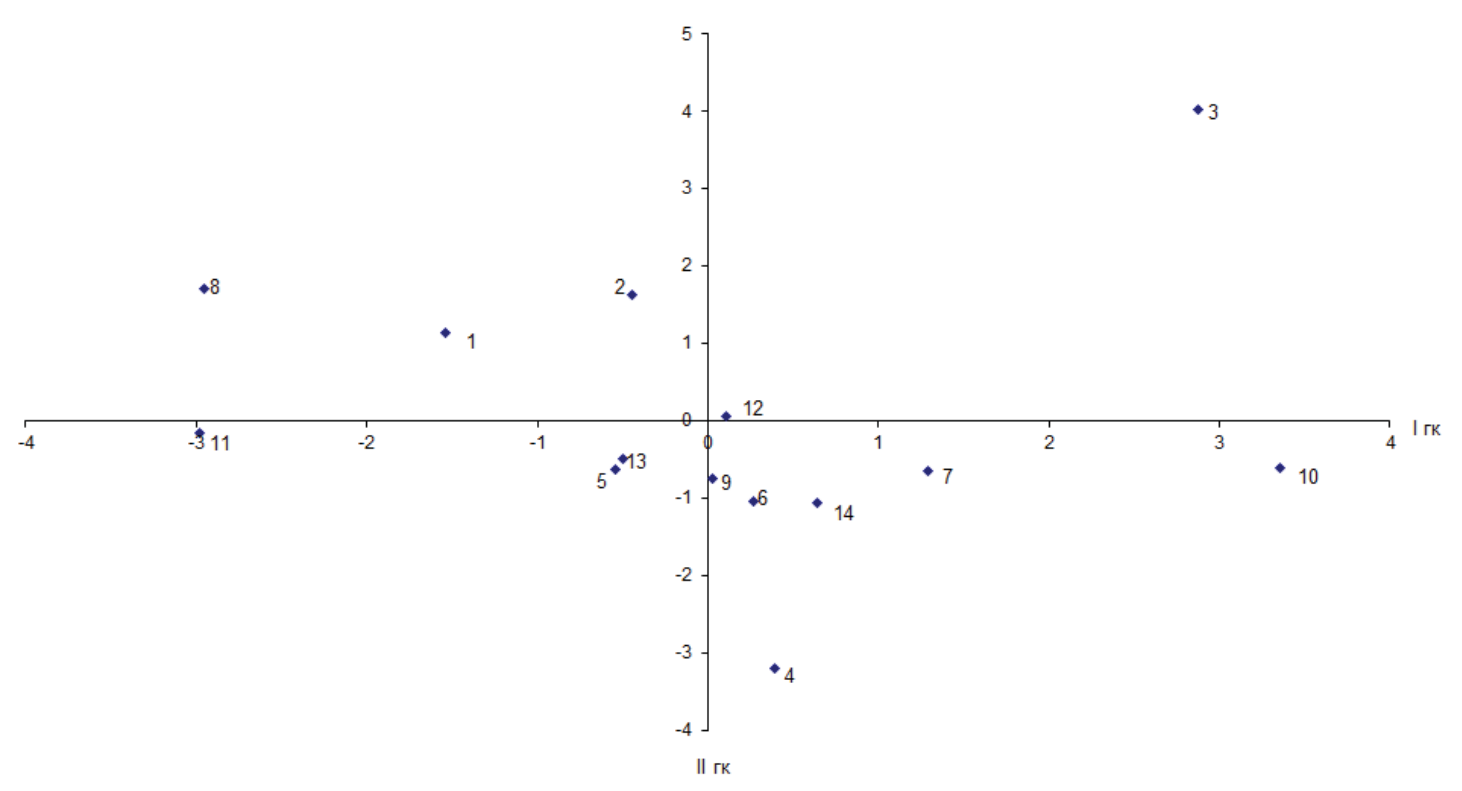

Рис. 1. Мужские черепа Ижевского могильника в пространстве двух первых главных компонентов. Обозначения могильников под номерами: 1 - пог. 9; 2 - пог. 17; 3 - пог. 38; 4 - пог. ?; 5 - пог. 43; 6 - пог. 62; 7 - пог. 66А; 8 - пог. 71; 9 пог. $105 ; 10$ - пог. $110 ; 11$ - пог. $125 ; 12$ - пог. $143 ; 13$ - пог. $180 ; 14$ - пог. 184.

Fig. 1. Male skulls from Izhevsk burial ground in the framework of the first two main components. The burial grounds are designated using the following numbers: 1 - burial $9 ; 2$ - burial $17 ; 3$ - burial $38 ; 4$ - burial $? ; 5$ - burial 43 ;

6 - burial $62 ; 7$ - burial 66A; 8 - burial $71 ; 9$ - burial 105; 10 - burial 110;11 - burial $125 ; 12$ - burial 143; 13 - burial 180;14 burial 184.

очередь также не были морфологически “чистыми”. Так, крайнее положение по осям I и II ГК занимают черепа из погребений № $38, ?, 71,110,125$ (на графике они под номерами $3,4,8,10$ и 11 соответственно). Черепа из погребений $38, ?, 110$ (3, 4 и 10) характеризуются как мезо-долихокранные с низким (высоким) и широким (узким) лицом (правая половина графика), а черепа из погребений 71 и 125 (8 и 11) сочетали широкое и низкое лицо с хорошо выступающим носом (левая сторона поля). Все остальные мужские черепа из погребений 43, 62, 66А, 105, 143, 180, 184 (5, $6,7,9,12,13$ и 14) занимают промежуточное положение, сочетая в себе те или иные черты указанных крайних вариантов.

Таким образом, морфологическое своеобразие мужской серии черепов Ижевского могильника состоит в ее смешанном характеpe. В основе этой неоднородности лежат как черепа европеоидного облика, но с разными краниометрическими характеристиками (длинноголовый - круглоголовый; широколицый - узколицый), так и черепа с чертами явно монголоидного типа (ослабленная горизонтальная профилировка, низкое переносье и небольшой угол выступания носа), которые, правда, не выступают в комплексе. Аналогичная ситуация отмечается и в женской группе ижевской серии. С той лишь разницей, что проявление монголоидных элементов здесь отмечается более отчетливо.

Для определения основных векторов этногенетических связей ижевской группы с синхронным ему населением был проведен межгрупповой анализ с привлечением мужских краниологических серий с территории Восточной Европы и Западной Сибири. Они характеризуют антропологический тип «местного» прикамско-приуральского населения различных археологических культур рубежа эр: пьяноборская, гляденовская, караабызская, азелинская, мазунинская, бахмутинская, ломоватовская (харинский этап). Также для сравнительного анализа были использованы серийные данные по поволжско-приуральским группам сармат среднего этапа и сборные серии по населению саргатской культуры Западной Сибири. Дополнительно в анализ были включены хронологически более поздние материалы Танкеевского могильника, которые, по мнению М.С. Акимовой, отражают генетическую связь между раннесредневековым населением Волго-Камья с предшествующим (Акимова, 1973).

Выяснение характера межгрупповой изменчивости и этногенетических связей населения рубежа эр определялось методом канонического анализа. В анализе использовались краниометрические параметры, имеющие повышенную таксономическую значи- 
Элементы первых трех канонически векторов (I-III) для 23 мужских краниологических серий эпохи ранлица 4. средневековья

Elements of the first three canonic vectors (I-III) for 23 male craniological series

Table 4. of the early medieval period

\begin{tabular}{|c|c|c|c|}
\hline Признаки & $\mathrm{I}$ & II & III \\
\hline 1. Продольный диаметр & -0.394 & 0.261 & 0.333 \\
\hline 8. Поперечный диаметр & $0.677^{*}$ & $-0.540 *$ & -0.170 \\
\hline 17. Высотный диаметр & -0.141 & 0.251 & 0.366 \\
\hline 9. Наименьшая ширина лба & -.0152 & -0.033 & -0.129 \\
\hline 45. Скуловой диаметр & -0.085 & 0.265 & -0.205 \\
\hline 48. Верхняя высота лица & -0.261 & -0.093 & 0.374 \\
\hline 51. Ширина орбиты & 0.798* & $0.518 *$ & 0.338 \\
\hline 52. Высота орбиты & -0.113 & -0.359 & 0.079 \\
\hline 54. Ширина носа & -0.064 & -0.030 & 0.185 \\
\hline 55. Высота носа & 0.101 & 0.059 & 0.359 \\
\hline 77. Назомалярный угол & 0.123 & 0.118 & 0.096 \\
\hline Zm’. Зигомаксиллярный угол & 0.131 & -0.003 & 0.243 \\
\hline SS:SC. Симотический указ-ль & 0.315 & 0.234 & -0.352 \\
\hline
\end{tabular}

*- выделены значения, указывающие на сильную коррелятивную связь

мость: $1,8,17,9,45,48,55,54,51,52,77, \mathrm{Zm}$, $\mathrm{SS}: \mathrm{SC}, 75(1)$. Каноническим методом извлечено три первых вектора, отражающих в сумме более $99 \%$ от всей межгрупповой изменчивости (табл. 4).

В первом каноническом векторе (более $65 \%$ от всей межгрупповой дисперсии) основные нагрузки падают на поперечный диаметр черепной коробки и ширину орбит. Их положительная взаимосвязь (более широким орбитам соответствует более широкая черепная коробка) позволяет выделить в анализируемой совокупности брахикранные и долихокранные серии. Второй канонический вектор (более $20 \%$ от всей изменчивости) выявляет отрицательную взаимосвязь между углом выступания носа и шириной мозговой капсулы, то есть с уменьшением угла носа уменьшается ширина черепа. Вероятно, данный вектор выделяет длинноголовые серии с небольшим углом выступанием носа и, наоборот, короткоголовые группы с более выступающим носом. Этот комплекс взаимосвязей, возможно, делит мужские краниологические выборки на серии с монголоидными и европеоидными особенностями. Третий канонический вектор (более $13 \%$ ) более четко разделяет сравниваемые краниологические серии на группы: с большим углом выступания носа («европеоидный градиент») и выборки с пониженными значениями угла носа («монголоидный» градиент).

Таким образом, канонический анализ показал, что межгрупповая изменчивость среди мужских краниологических групп эпохи железа с территории Восточной Европы и Западной Сибири зависит от формы черепа, ширины орбит и степени выступания носо- вых костей. Результаты межгруппового сравнения проиллюстрированы соответствующим графиком (рис. 2).

На графике, построенном в пространстве первых двух канонических векторов (рис. 2), крайние правые позиции занимают мужские серии саргатской культуры (3. Сибирь), для которых характерна брахикранная форма черепа, относительно широкое и относительно низкое лицо со слабой горизонтальной профилировкой и небольшой угол выступания носа. Особую компактную группу на графике занимают нижневолжские сарматы среднего этапа. Они характеризуются мезобрахикранией, относительно широким и относительно низким и хорошо профилированным лицом в сочетании с высоким переносьем и большим углом носа. Серия из Ижевского могильника по своим морфологическим особенностям - удлиненная форма черепа, узкое и средневысокое лицо в сочетании с умеренной горизонтальной профилировкой и средним выступанием носовых костей входит в круг поволжско- приуральских серий эпохи рубежа эр, которые представляют, в антропологическом плане, население пьяноборской, мазунинской, караабызской, азелинской, гляденовской и бахмутинской культур. Вероятно, формирование физического облика данного населения проходило на общей морфологической основе (европеоидной в целом), что, впрочем, не исключает генетического влияния отдельных «южных» европеоидных и более монголоидных «восточных» групп.

Был проведён палеопатологический анализ останков ижевского могильника. Доступ- 


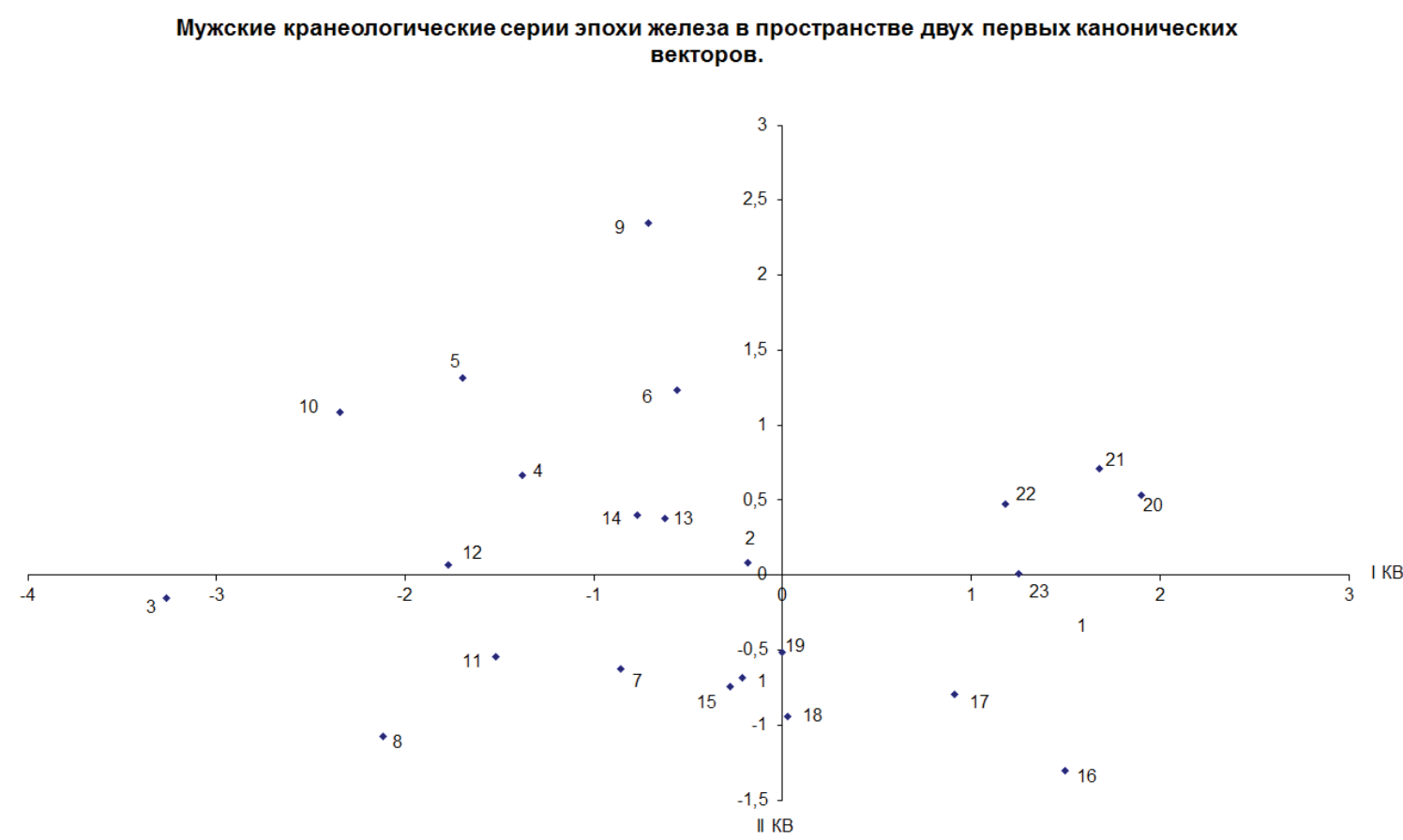

Рис. 2. Мужские краниологические серии эпохи железа в пространстве двух первых канонических векторов. Обозначение серий под номерами: 1 - Танкеевский могильник; 2 - Объединенная серия («Городок», «Заосиново I, IV», «Верхний Ирьяк»); 3 - Кушулевский м-к; 4 - Чегандинский м-к; 5 - Камышлы-Тамакский м-к; 6 - Старо-Чекмакский м-к; 7 - Шиповский м-к; 8 - Охлебининский м-к; 9 - Мари-Луговской м-к; 10 - Азелинский, Суворовский м-ки; 11 - Ижевский м-к; 12 - Покровский м-к; 13 - Боярский «Арай» м-к; 14 - Бирский м-к (ранний); 15 - Митинский м-к; 16 - Старо-Киишкинский м-к; 17 -

Заволжская группа (сборная); 18 - Калмыцкая группа (сборная); 19 - Донская (сборная); 20 - Исето-Тобольская группа (сборная); 21 - Приишимская группа (сборная); 22 - Прииртышская группа (сборная); 23 - Барабинская группа (сборная). Fig. 2. Male craniological series of the Iron Age in the framework of the first two canonical vectors. The series are designated using the following numbers: 1 - Tankeevka burial ground; 2 - Composite series ("Gorodok", "Zaosinovo I, IV", "Verkhny Iryak"); 3 Kushulevo burial ground; 4 - Cheganda burial ground; 5 - Kamyshly-Tamak burial ground; 6 - Stary Chekmak burial ground; 7 Shipovo burial ground; 8 - Okhlebinino burial ground; 9 - Mari-Lugovaya burial ground; 10 - Azelino, Suvorovsky burial grounds; 11 - Izhevsk burial ground; 12 - Pokrovsky burial ground; 13 - Boyarsky "Arai" burial ground; 14 - Birsk burial ground (early); 15 - Mitino burial ground; 16 - Starye Kiishki burial ground; 17 - Trans-Volga group (composite); 18 - Kalmyk group (composite); 19 - Donskaya (composite); 20 - Iset' River-Tobolsk group (composite); 21 - Ishim River group (composite); 22 - Irtysh River group (composite); 23 - Baraba Lowland group (composite).

ны для анализа оказались 42 черепа (из них мужских 20, женских 21, детский 1), скелетов всего 74 (мужских 28, женских 29, детских 6, неопределённых в силу комплектности и сохранности - 10). Неопределённые неполные костяки не исключались из анализа, поэтому при подсчёте результатов разбивка по полу не производилась. Также следует оговориться, что, хотя всего исследовалось 83 индивида, не все костяки комплектовались черепами и не каждый череп сопровождался костяком. Отмечались травмы (с медико-криминалистической реконструкцией их возникновения) и их следствия - воспалительные осложнения, а также возрастные изменения и маркёры физиологического стресса. Для более подробной характеристики повреждений была произведена рентгенография интересующих костей с использованием рентгеновского аппарата «Мобирен-МТ».

Индивид из пог. 167 (мужчина около 30 лет) имел на черепе разруб от удара плоским предметом с продолговатой контактирующей поверхностью в направлении слева направо, сверху вниз и снаружи внутрь (рис. 3А1, А2). Длина следообразующей части этого предмета ок. 9 см, ширина 0,1 см. Удар пришёлся в левую лобно-теменную область либо прижизненно, либо в момент смерти (нет следов переживаемости). Похожую травму, разруб в области чешуи лобной кости (вероятно, тем же орудием), имел индивид из пог. 184 (мужчина около 25 лет), направление нанесения удара: спереди назад, слева направо и снаружи внутрь (рис. 3Б). Длина погрузившейся части травмирующего предмета ок. 5,5 см. У индивида из пог. 44 (мужчина 35 лет) отмечена деформация передней стенки правой верхнечелюстной пазухи (размерами $19 \times 15 \times 4$ мм) с утолщением по подглазничному краю $19 \times 11 \times 3$ мм) (на рис. 3В1 отмечены стрелками, рис 3В2 демонстрирует область в большем масштабе), что является результатом травмы правой челюстно-скуловой области, вероятно, в результате удара. Рентгенограмма рис. 3В3 демонстрирует истончение верхнечелюстной пазухи и соответствующее утолщение (рентгеноплотная область) в области 


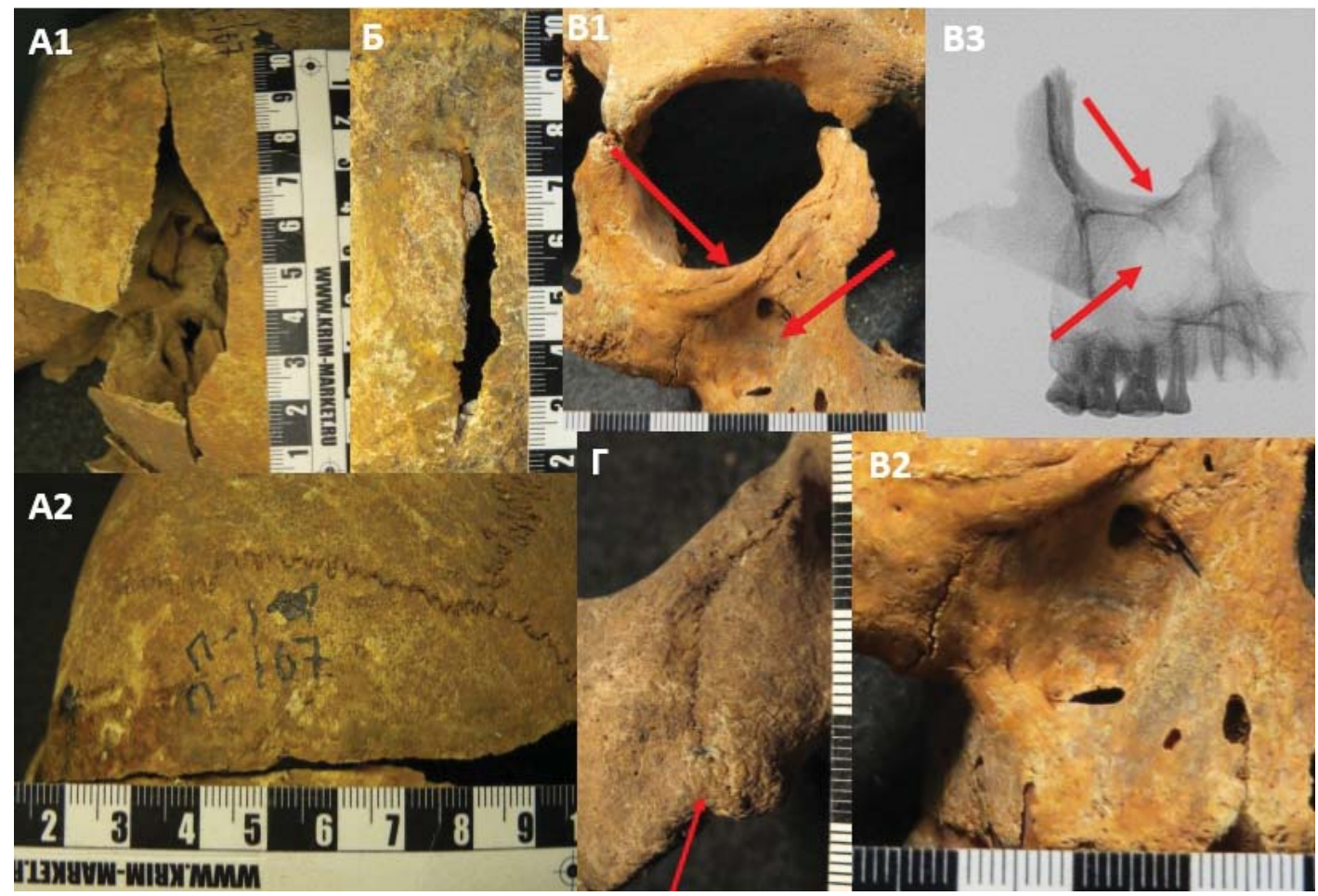

Рис. 3. Травматические повреждения на черепах из Ижевского могильника: $A 1, A 2$ - разруб в лобно-теменной области на черепе из пог. $167 ; 5$ - разруб на лобной кости черепа из пог. $184 ; B 1, B 2$ - травма правой челюстно-скуловой области на черепе из пог. 44, стрелками отмечены соответствующие деформационные изменения (см. текст); В3 - рентгенограмма травма правой челюстно-скуловой области на черепе из пог. 44, стрелками отмечены соответствующие деформационные изменения (см. текст); $Г$ - травма правой скуловой области у индивида из пог. 71, стрелкой отмечена костная мозоль.

Fig. 3. Traumatic injuries on the skulls from Izhevsk burial ground: $A 1, A 2$ - cut in the fronto-parietal region on the skull from burial $167 ; 5$ - cut on the frontal bone of the skull from burial $184 ; B 1, B 2$ - injury in the right maxillojugal area on the skull from burial 44, arrows mark the corresponding deformation changes (ref. text); B3-X-ray image of an injury of the right maxillojugal area on the skull from burial 44, arrows mark the corresponding deformation changes (ref. text); $\Gamma$-injury to the right malar region of the person from burial 71, the arrow marks a callus.

подглазничного края (отмечены стрелками). У индивида из пог. 71 (мужчина 35 лет) также была обнаружена деформация в правой верхнечелюстной области. Предположительно она является результатом травмы правой скуловой области с расхождением швов. Имеется костная мозоль в районе верхнечелюстного шва (отмечена стрелкой на рис. ЗГ).

Таким образом, 4 из 42 черепов ижевского могильника (9,5\%) несут на себе следы травматических повреждений, все были определены как мужские (итого $20 \%$ мужских черепов с травмой).

Далее на предмет травм были обследованы скелеты. В останках из погребения 23 (предположительно, женских) левая лопатка имела сквозное отверстие на акромионе (входное отверстие размерами $12 \times 8,5$ мм, выходное $11 \times 7$ мм), с признаками заживления и развития воспалительного процесса (рис. 4A1). Выявленное повреждение прижизненное, от действия предмета с ограниченной контактирующей поверхностью, размерами не более $12 \times 8,5$ мм. При этом преимущественное направление воздействия: сзади наперёд и сверху вниз (рис. 4А2, зонд в месте дефек- та указывает, как располагался и куда был направлен травмирующий предмет). Интерес представляет также левая ключица того же индивида: на акромиальном её конце, снизу, на расстоянии 11 мм от края, обнаруживается костная мозоль (вероятно, имел место неполный перелом) (рис. 4А3, отмечена стрелкой). Таким образом, индивид прижизненно подвергся удару стрелы (?) с левой стороны со спины сверху, которая вошла, пробив акромиальный конец лопатки насквозь и упёрлась в ключицу. Скорее всего, травмирующий объект был извлечён, впоследствии развилось воспаление, приведшее к сильной боли и временному ограничению подвижности в левом плечевом суставе верхней конечности.

У индивида из пог. 67 (вероятно, женщина) был выявлен сросшийся перелом правой локтевой кости (рис. 4Б1), являющийся результатом локального удара/падения на руку (очаг сжатия-растяжения) - изгиб поперечный/продольный (внутри кости полость размерами $27 \times 15 \times 22$ мм, предположительно результат осложнения - остеомиелита, отмечена стрелкой) (рис. 4Б2). Лучевая кость в целостном состоянии не представлена. 


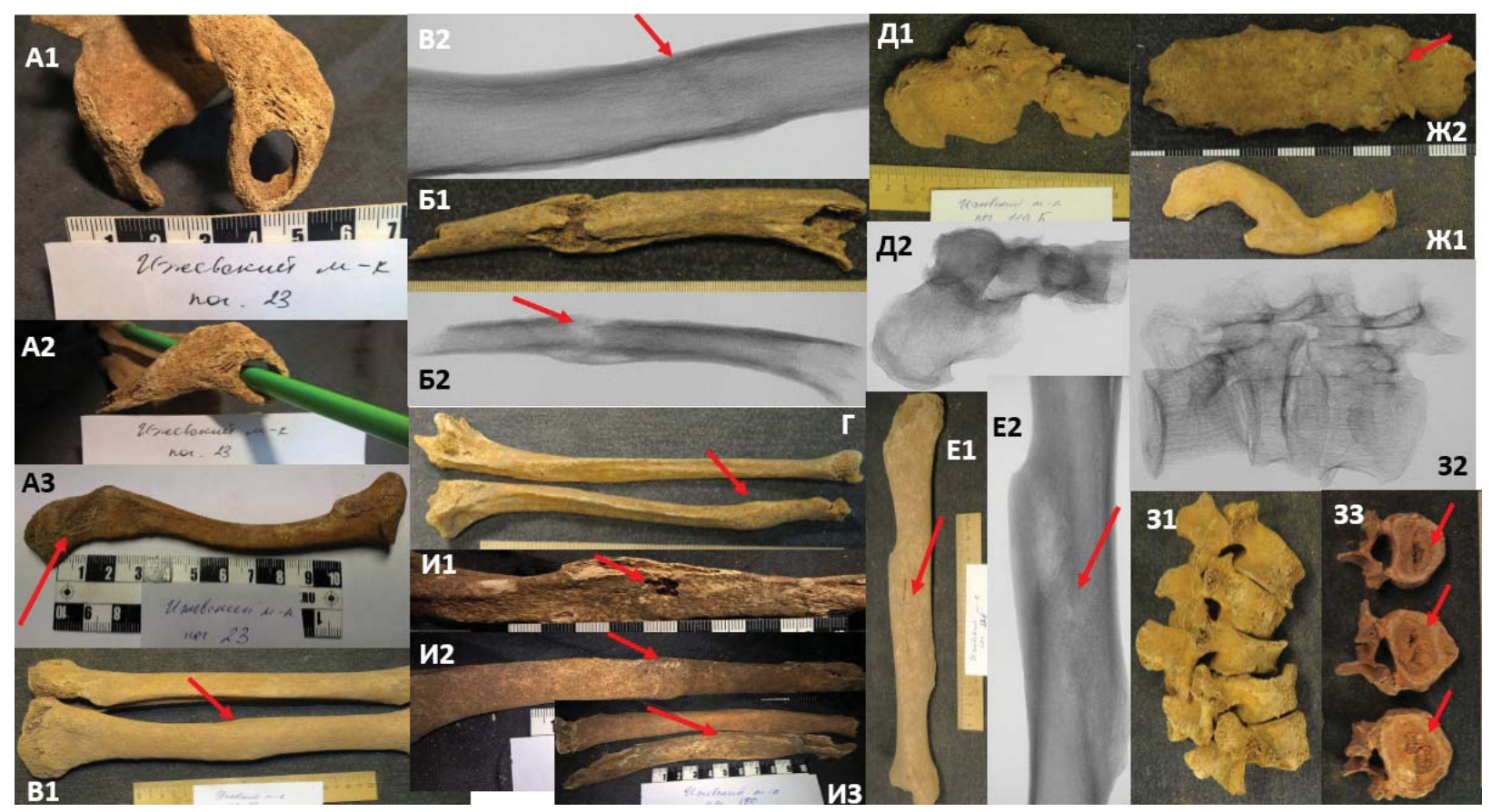

Рис. 4. Травмы скелета: $A 1$ - левая лопатка индивида из пог. 23, акромион; $A 2$ - акромион с зондом в месте дефекта; $A 3$

- левая ключица, стрелкой отмечена костная мозоль; $Б 1$ - перелом правой локтевой кости у индивида из пог. $67 ; 52$ рентгенограмма перелома локтевой кости у индивида из пог. 67 , стрелкой отмечена полость от развившегося остеомиелита; B1 - сросшийся неполный перелом левой большеберцовой кости у индивида из пог. 88, стрелкой отмечена костная мозоль;

$B 2$ - рентгенограмма перелома левой большеберцовой кости у индивида из пог. 88 , стрелкой отмечена рентгеноплотная линия в области формирования костной мозоли; $\Gamma$ - сросшийся перелом правой локтевой кости, стрелкой отмечена костная мозоль; Д1 - сращение плюсневых костей левой ноги у индивида из пог. 119Б; Д2 - рентгенограмма сращения плюсневых костей левой ноги у индивида из пог. 119Б; $E 1$ - сросшийся перелом правой большеберцовой кости у индивида из пог. 128 , стрелкой отмечена линия смещения отломков и образования костной мозоли; E2 - рентгенограмма сросшегося перелома правой большеберцовой кости у индивида из пог. 128, стрелкой отмечена рентгеноплотная линия в области формирования

костной мозоли; Ж1 - сросшийся полный перелом правой ключицы у индивида из пог. 136; Ж2 - неполный перелом грудины у индивида из пог. 136; 31 - компрессионный перелом поясничного отдела позвоночника; 32 - ренгенограмма поясничного отдела позвоночника; 33 - 2-й, 3-й и 4-й поясничные позвонки (сверху вниз соответственно) с деформациями, которые отмечены стрелками; И1 - заросший перелом правой локтевой кости у индивида из пог. 180, свищевой ход отмечен стрелкой; И2 - заросший перелом правой локтевой кости у индивида из пог. 180, костная мозоль отмечена стрелкой; И3 заросший перелом правой лучевой кости, костная мозоль отмечена стрелкой.

Fig.4. Skeleton injuries. $A 1$ - left shoulder blade of the person from burial 23, acromion: $A 2$ - acromion with a probe at the defect site; $A 3$ - left clavicle, arrow marks the callus; $D 1$ - fracture of the right elbow bone of the person from burial $67 ; 52-\mathrm{X}$-ray of an elbow bone fracture of the person from burial 67, arrow marks the cavity from developed. osteomyelitis; B1 - fused incomplete fracture of the left tibia of the person from burial 88, arrow marks the callus; B2 - X-ray image of a fracture of the left tibia of the person from burial 88, arrow marks the X-ray dense line in the callus formation area; $Д$ - fused fracture of the right elbow bone, the callus is marked with an arrow; Д1 - fusion of the metatarsal bones of the left leg of the person from burial 119Б; Д2 - Х-ray image of a fusion of the metatarsal bones in the left leg of the person from burial 119Б; $E 1$ - fused fracture of the right shin bone of the person from burial 128, arrow marks the displacement line of the fragments and callus formation; E2 - X-ray image of a fused fracture of the right tibia of the person from burial 128, arrow marks the X-ray dense line in the callus formation area; $\Gamma 1$ - fused complete fracture of the right clavicle of the person from burial 136; Ж2 - incomplete sternum fracture of the person from burial 136; 31 - compression fracture of the lumbar spine; 32 - X-ray of the lumbar spine; 33 - 2nd, 3rd and 4th lumbar vertebrae (top to bottom, respectively) with deformations marked with arrows; $И 1$ - overgrown fracture on the right elbow bone of the person from burial 180 , the fistulous tract is marked with an arrow; И2 - overgrown fracture of the right elbow bone of the person from burial 180, arrow marks the callus; И3 - overgrown fracture of the right radius, arrow marks the callus.

У индивида из пог. 88 (пол не определяется) имеется костная мозоль на левой большеберцовой кости (рис. 4В1, В2), перелом был неполным, так как нет укорочения кости и смещения отломков (для сравнения приложена правая большеберцовая кость того же индивида). Удар пришёлся снаружи внутрь, слева направо в область средней трети кости, вид деформации - поперечный изгиб. Малая берцовая кость при этом воздействии также должна была сломаться (не представлена).

У индивида из пог. 110 (мужчина около 25 лет) на правой локтевой кости имеется кост- ная мозоль (рис. 4Г, указана стрелкой, рядом приложена левая локтевая кость для сравнения). Удар пришёлся в сторону нижней трети предплечья по внутренней поверхности, в результате произошло укорочение кости и деформация кзади (перелом, вероятно, был полный, но благополучно сросся), линия перелома, скорее всего, была поперечной. Подобная травма могла быть получена от удара или падения на руку.

У индивида из пог. 119 Б наблюдается сращение плюсневых костей левой ноги, является результатом остеомиелита, воспаления в 


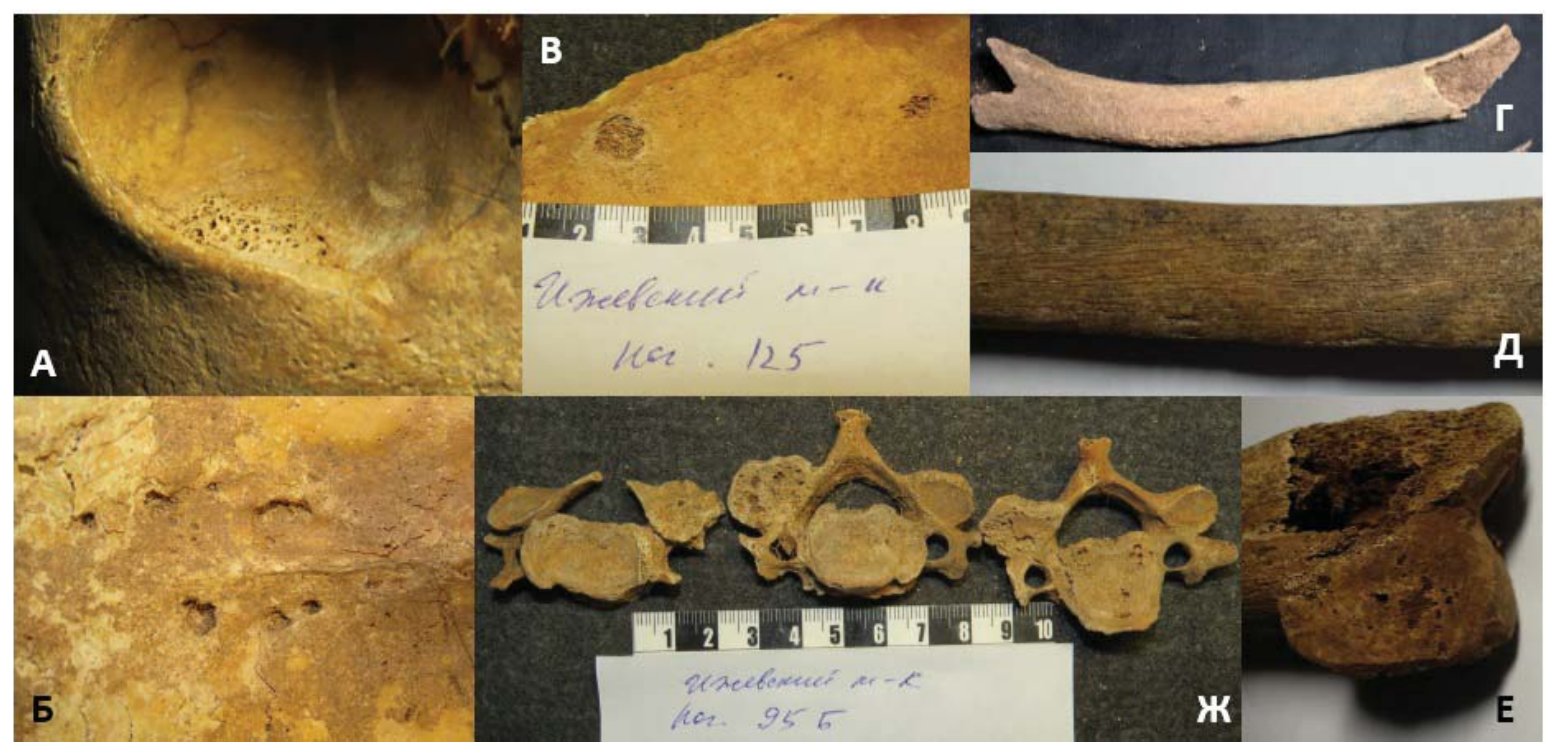

Рис. 5. Маркеры физиологического стресса и возрастных изменений: $A-c r$. orbitalia у индивида из пог.78; $D$ - пахионовы грануляции на эндокране лобной кости у индивида из пог. $105 ; B$ - очаги порозности на эндокране лобной кости у индивида из пог. $125 ; \Gamma$ - деформация бедренной кости у индивида из пог. $79 \mathrm{~A} ;$ Д - периостит на бедренной кости индивида из пог. $149 ; E$ - артроз коленного сустава у индивида из пог. $180 ; \mathcal{K}$ - остеохондроз шейного отдела позвоночника у индивида из пог. 95Б.

Fig. 5. Markers of physiological stress and age-related changes: $A-c r$. orbitalia of the person from burial $78 ; B-$ pachyon granulations on the endocrane of the frontal bone of the person from burial $105 ; B$ - porosity foci on the endocrane of the frontal bone of the person from burial $125 ; \Gamma$ - femur deformation of the person from burial 79A; $Д$ - deformation - periostitis on the femur of the person from burial 149; $E$ - knee joint arthrosis of the person from burial $180 ; \mathcal{W}$ - osteochondrosis of the cervical spine of the person from burial 95B.

голеностопном суставе, что могло стать отдалённым последствием травмы (рис. 4Д1, Д2).

У индивида из пог. 128 имеется перелом правой большеберцовой кости (рис. 4Е1, E2). Перелом диафиза средней трети правой большеберцовой кости косо-продольный, со смещением отломков и формированием костной мозоли. Удар пришёлся под острым углом.

У индивида из пог. 136 (мужчина около 45 лет) выявлен сросшийся полный перелом правой ключицы (с укорочением и неправильным срастанием, рис. 4Ж1), неполный перелом грудины (рис. 4Ж2) с деформацией, компрессионный перелом позвоночника в поясничном отделе (2, 3-й поясничные позвонки клиновидная деформация, 4-й - деформация в центре) (рис. 431, 32, 33). На рентгенограмме (рис. 432) показаны уменьшение высоты тел позвонков, уменьшение плотности губчатой ткани в деформированных зонах. Механизм образования подобной травмы: чрезмерное сгибание туловища в поясничном отделе кпереди в сочетании с осевым нагружением. Падение на ноги с высоты либо падение на ягодицы. Перелом ключицы мог произойти при ударе в руку с местом приложения силы к головке плечевой кости (могло быть результатом падения набок) либо при падении на отведённую в локтевом суставе руку, при этом ключица испытывает осевое нагружение.

У индивида из пог. 180 (мужчина около 50 лет) отмечен заросший перелом правой локте- вой и лучевой костей с осложнением в виде остеомиелита и свищевым ходом на локтевой кости (рис. 4И1, И2). Правая лучевая кость также имеет признаки заросшего перелома в виде костной мозоли (рис. 4И3, рядом приложена целая левая лучевая кость). Вероятно, неполный перелом произошёл с местом воздействия в область внутренней поверхности предплечья (резкий удар по руке в средней её трети, либо падение на руку - в этом случае рука должна быть согнута в локтевом суставе и повёрнута кнутри).

Таким образом, 8 скелетов имеют следы травматических повреждений из 74 (10,81\%).

На следующем этапе рассматривались маркёры физиологического стресса. У 4-х индивидов были выявлены выраженные гиперостозы в области глазниц - cr.orbitalia, являющаяся маркером анемий: череп из пог. 43 (мужчина, около 25 лет) - 2 балла, череп из пог. 87 (мужчина, около 35 лет) - 2 балла, череп из пог. 180 (мужчина, около 50 лет) - 2 балла, череп из пог. 78 (ребёнок, около 9 лет) 2-3 балла (рис. 5A). Порозность на эндокране лобной кости была выявлена у 5 индивидов: череп из пог. 80 (женщина, около 25 лет), череп из пог. 105 (женщина, около 25 лет), череп из пог. 124 (женщина, около 25 лет), череп из пог. 125 (мужчина, около 35 лет), череп из пог. 138 (мужчина, около 35 лет). Характерная локализация порозности сосудистого генеза (пахионовых грануляций) наблюдается у 4-х инди- 
видов (рис. 5Б), у одного индивида (пог. 125) - выраженная очаговость мелкой порозности, напоминающая результат инфекционновоспалительного процесса (рис. 5В). Таким образом, 4 из 42 черепов ижевского могильника $(9,5 \%)$ имеют признаки сосудистых нарушений (1 мужской из $20-5 \%$; и 3 женских из $21-14,29 \%)$.

Обращают на себя внимание многочисленные деформации длинных костей скелета - остеомаляция (например, бедренная кость индивида из пог. 79А, рис. 5Г), являющаяся признаком недостаточной минерализации костной ткани в силу тех или иных причин, зафиксирована у $28,37 \%$ взрослых (21 случай из 74) и у $16,66 \%$ детей (1 случай из 6).

Периоститы - маркёры пищевых стрессов, неспецифических воспалений и интоксикаций - выявлялись на длинных костях в 49,3\% случаях, где сохранность надкостницы позволяла провести определение (34 случая из 69) (например, бедренная кость индивида из пог. 149, рис. 5Д).

Возрастные изменения в виде артрозов суставов, остеофитов и грыж Шморля на позвонках были отмечены на костяках 13 индивидов $(17,56 \%)$, при этом артрозы коленного сустава (рис. 5Е) и остеохондроз позвоночни- ка (рис. 5Ж) встречается в 9 случаях (12,16\%). Все индивиды, у которых были обнаружены указанные изменения, старше 30 лет.

Таким образом, был осуществлён палеопатологический анализ останков ижевского могильника. Были зафиксированы и охарактеризованы травмы (с медико-криминалистической реконструкцией их возникновения) и их следствия - воспалительные осложнения, а также возрастные изменения и маркёры физиологического стресса. Изменения, соответствующие возрастной норме, были отмечены у $17,56 \%$ индивидов. Было выявлено 9,5\% черепов с признаками травм, вероятно, боевых, 10,81\% посткраниальных скелетов с признаками переломов и травм (одна из которых, возможно, боевая - удар стрелы), высокий уровень остеомаляции $(28,37 \%$ у взрослых и $16,66 \%$ у детей) вследствие метаболических нарушений, скорее всего, способствовал более частому и осложнённому травматизму; почти половина случаев периоститов, наличие cr.orbitalia и внутричерепных кровоизлияний говорит о неблагоприятных условиях жизни, анемиях и недоедании в популяции, захороненной в ижевском могильнике мазунинской эпохи.

\section{Список мужских краниологических серий эпохи рубежа эр, привлеченных для межгруппового анализа.}

Танкеевский могильник, IX-X вв. (Акимова, 1973; Газимзянов, 2018).

Гляденовская культура

Сборная серия («Городок», «Заосиново I, IV», «В. Ирьяк»), III в. до н. э. - V-VI вв. н. э. (неопубликованные данные И.Р. Газимзянова).

Пьяноборская культура

Кушелевский м-к, І в. до н. э. - ІІІ в. н. э. (Ефимова, 1991).

Чегандинский м-к, III в. до н. э. - II в. н. э. (Акимова, 1968; Фаттахов, 1981).

Камышлы-Тамакский м-к, II в. до н. э. - ІІ в. н. э. (Акимова, 1968).

Старо-Чекмакский м-к, II в. до н. э. - II в. н. э. (Фаттахов, 1981).

Караабызская культура

Шиповский м-к, IV-III вв. до н. э. (Ефимова, 1981).

Охлебининский м-к, І в. до н. э. - II в. н. э. (Ефимова, 1981).

Азелинская культура

Мари-Луговской могильник, IV-V вв. н. э. (Алексеев, 1962).

Азелинский, Суворовский могильники (объединенная серия), III - сер. V в. н. э. (Акимова, 1961).

Мазунинская культура

Ижевский м-к, III-V вв. н. э. (Фаттахов, 1978).

Покровский м-к, IV-V вв. н. э. (Фаттахов, 1978).

Боярский «Арай» м-к, III-IV-V вв. н. э. (Широбоков, Черных, 2016).

Бахмутинская культура

Бирский м-к (ранний), III-V вв. н. э. (Акимова, 1968).

Харинская культура

Митинский м-к, IV-V вв. н. э. (Акимова, 1968).

Сарматы (средний этап)

Старо-Киишкинский м-к, III-II в. до н. э. (Акимова, 1968).

Заволжская группа (сборная серия), II в. до н. э. - II в. н. э. (Балабанова, 2000).

Калмыцкая группа (сборная серия), ІІ в. до н. э. - II в. н. э. (Балабанова, 2000).

Донская (сборная), II в. до н. э. - II в. н. э. (Балабанова, 2000).

Саргатская культура

Исето-Тобольская группа (сборная), IV в. до н. э. - V в. н. э. (Багашев, 2000). 
Приишимская группа (сборная), V в. до н. э. - III-IV вв. н. э. (Багашев, 2000).

Прииртышская группа (сборная), VI-V вв. до н. э. - III-IV вв. н. э. (Багашев, 2000).

Барабинская группа (сборная), VI-V вв. до н. э. - I в. н. э. (Багашев, 2000).

\section{ЛИТЕРАТУРА}

Акимова М.С. Антропологические материалы из Танкеевского могильника // ВА. 1973. Вып. 45 C. $15-29$.

Акимова М.С. Антропологический состав населения пьяноборской культуры // ВА. 1961. Вып. 7. C. 29-39.

Акимова М.С. Антропология древнего населения Приуралья. М.: Наука, 1968. 120 с.

Алексеев В.П. Палеоантропологический материал из Мари-Луговского могильника // Железный век Марийского края / Труды МАЭ. Т. ІІ / Отв. ред. Г.А. Архипов. Йошкар-Ола: Мар. кн. изд-во, 1962. C. 241-258.

Алексеев В.П., Дебеи Г.Ф. Краниометрия. Методика антропологических исследований. М.: Наука, 1964. $128 \mathrm{c}$.

Багашев А.Н. Палеоантропология Западной Сибири: Лесостепь в эпоху раннего железа. Новосибирск: Наука, 2000. 374 с.

Балабанова М.А. Антропология древнего населения Южного Приуралья и Нижнего Поволжья. Ранний железный век. М.: Наука, 2000. 133 с.

Бужилова А.П. Ноmo sapiens: История болезни. М.: Языки славянской культуры, 2005. 320 с.

Бужилова А.П., Козловская М.В., Лебединская Г.В., Медникова М.Б. Историческая экология человека. Методика биологических исследований. М.: Старый Сад, 1998, 260 с.

Газимзянов И.Р. Антропология Танкеевского могильника: краниологический анализ старых и новых материалов // Поволжская археология. 2018. № 1(23). С. 294-320.

Диагностикум механизмов и морфологии переломов при тупой травме скелета. Изд. 2-е, перераб. Новосибирск: Наука, 2011. 522 с.

Ефимова С.Г. К краниологии Волго-Камья эпохи раннего железа // ВА. 1981. Вып. 67. С. 64-73 .

Ефимова С.Г. Палеоантропология Поволжья и Приуралья. М.: Изд-во МГУ, 1991. 95 с.

Перерва E.B. Маркеры стресса как индикаторы адаптации (по материалам золотоордынского могильника Маячный бугор) // Микроэволюционные процессы в человеческих популяциях / Отв. ред. А.В. Громов, В.И. Хартанович. СПб.: МАЭ РАН, 2009. 293 с.

Фаттахов Р.М. Антропологическая характеристика населения Удмуртского Прикамья середины І тыс. н. э. // Проблемы этнографии и этнической антропологии / Отв. ред. А.А. Воронов, И.И. Крупник. М.: Наука, 1978. С. 206-215.

Фаттахов Р.М. Краниологическая характеристика материалов могильника Старый Чекмак // Об исторических памятниках по долинам Камы и Белой / Отв. ред. А.Х. Халиков. Казань: Изд-во ИЯЛИ КФАН СССР, 1981. С. 94-109.

Фаттахов Р.М. Новые антропологические материалы со Средней и Нижней Камы // Сборник музея по антропологии и этнографии. Вып. XXXVI. Л.: Наука, 1980. С. 130-138.

Широбоков И.Г., Черных E.M. Данные физической антропологии и проблема формирования населения Прикамья середины I тысячелетия н.э. (по материалам Боярского «Арай» могильника) // Вестник Удмуртского университета. Сер. История и филология. 2016. Т. 26. Вып. 1. С. 25-34.

\section{Информация об авторах:}

Волкова Елизавета Валерьевна, научный сотрудник отдела средневековой археологии, Институт археологии им. А.Х. Халикова Академия наук Республики Татарстан (г. Казань, Россия); erminea.wolf@gmail.com

Газимзянов Ильгизар Равильевич, кандидат исторических наук, независимый исследователь (г. Казань, Россия); g-ilgizar@yandex.ru

Кирягин Константин Валерьевич, лейтенант юстиции, старший эксперт отделения судебномедицинских исследований ЭКО СУ СК РФ по Республике Татарстан (г. Казань, Россия); kiryagin@mail.ru

Калянов Виктор Александрович, ассистент кафедры судебной медицины ФГБОУ ВО «Казанский государственный медицинский университет» Минздрава РФ (г. Казань, Россия); Black-diver@mail.ru

\section{REFERENCES}

Akimova, M. C. 1973. In Voprosy antropologii (Issues of Anthropology) (45), 15-29 (in Russian).

Akimova, M. C. 1961. In Voprosy antropologii (Issues of Anthropology) (7), 29-39 (in Russian).

Akimova, M. S. 1968. Antropologiia drevnego naseleniia Priural'ia (Anthropology of the Ancient Population of the Cis-Urals) (in Russian).

Alekseev,V. P. 1962. In Arkhipov, G. A. (ed.). Trudy Mariiskoi arkheologicheskoi ekspeditsii (Proceedings of Mari Archaeological Expedition) II. Yoshkar-Ola: "Mariiskoe knizhnoe izdatel'stvo" Publ., 241-258 (in Russian). 
Alekseev, V. P., Debets, G. F. 1964. Kraniometriia. Metodika antropologicheskikh issledovanii (Craniometry. Anthropologic Research Technique). Moscow: "Nauka" Publ. (in Russian).

Bagashev, A. N. 2000. Paleoantropologiya Zapadnoy Sibiri: Lesostep'v epokhu rannego zheleza (Paleoanthropology of Western Siberia: Forest-Steppe Area in the Early Iron Age). Novosibirsk: "Nauka" Publ. 537 (in Russian).

Balabanova, M. A. 2000. Antropologiya drevnego naseleniya Yuzhnogo Priural'ya i Nizhnego Povolzh'ya. Ranniy zhelezniy vek (Anthropology of the Ancient Population of the Southern Urals and the Lower Volga Region. The Early Iron Age). Moscow: "Nauka" Publ. (in Russian).

Buzhilova, A. P. 2005. Homo Sapiens: Istoriia bolezni (Homo Sapiens: a Medical History). Moscow: "Iazyki slavianskoi kul'tury" Publ. (in Russian).

Buzhilova, A. P., Kozlovskaia, M. V., Lebedinskaia, G. V., Mednikova, M. B. 1998. Istoricheskaia ekologiia cheloveka. Metodika biologicheskikh issledovanii (Historical Ecology of Humans: Methodology of Biological Research). Moscow: "Staryi Sad" Publ. (in Russian).

Gazimzyanov, I. R. 2018. In Povolzhskaya arkheologiya (Volga River Region Archaeology) 23 (1), 294-320 (in Russian).

Diagnostikum mekhanizmov i morfologii perelomov pri tupoi travme skeleta (Diagnostic of Mechanisms and Morphology of Fractures in Case of Blunt Trauma of Skeleton). 2011. Novosibirsk: "Nauka" Publ. (in Russian).

Efimova, S. G. 1981. In Voprosy antropologii (Issues of Anthropology) (67), 64-73 (in Russian).

Efimova, S. G. 1991. Paleoantropologiia Povolzh'ia i Priural'ia (Paleoanthropology of the Volga Region and the Urals). Moscow: Moscow State University Publ. (in Russian).

Pererva E. V. 2009. In Gromov, A. V., Khartanovich, V. I. (eds.). Mikroevoliutsionnye protsessy v chelovecheskikh populiatsiiakh (Micro-Evolutionary Processes in Human Populations). Saint Petersburg: Peter the Great Museum of Anthropology and Ethnography (Kunstkamera) of Russian Academy of Sciences (in Russian).

Fattakhov, R. M. 1978. In Voronov, A. A. (ed.). Problemy etnografii i etnicheskoi antropologii (Issues of Ethnography and Ethnic Anthropology). Moscow: "Nauka" Publ., 206-215 (in Russian).

Fattakhov, R. M. 1981. In Khalikov, A. Kh. (ed.). Ob istoricheskikh pamiatnikakh po dolinam Kamy i Beloi (On the Historical Sites in Kama and Belaya River Valleys). Kazan: Kazan Branch of the Academy of Sciences of the USSR, Language, Literature and History Institute, 94-109 (in Russian).

Fattakhov, R. M. 1980. In Sbornik muzeia po antropologii i etnografii (Collected Papers of the Museum for Anthropology and Ethnography) XXXVI. Leningrad: "Nauka" Publ., 130-138 (in Russian).

Shirobokov, I. G., Chernykh, E. M. 2016. In Vestnik Udmurtskogo universiteta. (Bulletin of Udmurt University) 26 (1), 25-34 (in Russian).

\section{About the Authors:}

Volkova Elizaveta V. Institute of Archaeology named after A.Kh. Khalikov, Academy of Sciences of the Republic of Tatarstan. Butlerov St., 30, Kazan, 420012, the Republic of Tatarstan, Russian Federation; erminea.wolf@gmail.com

Gazimzyanov Ilgizar R., Candidate of Historical Sciences, Independent researcher. Kazan, Russian Federation; g-ilgizar@yandex.ru

Kiryagin Konstantin V. Lieutenant of Justice, senior expert of the Department of Forensic Medical research of the Investigative Department of the Investigative Committee of the Russian Federation for the Republic of Tatarstan, Bolshaya Krasnaya Str. 39, Kazan, 420015, the Republic of Tatarstan, Russian Federation; kiryagin@mail.ru

Kalyanov, Viktor A. Kazan State Medical University. Butlerov St., 49, Kazan, 420012, the Republic of Tatarstan, Russian Federation; Black-diver@mail.ru

Статья поступила в журнал 01.08.2020 г.

Статья принята к публикации 01.09.2020 г.

Авторы внесли равноценный вклад в работу. 